\title{
Döviz Kuru Volatilitesinin Katılım Bankalarının Kredileri Üzerine Etkisi
}

\author{
The Impact Of Exchange Rate Volatility On Participant Banks Credit
}

\author{
Mercan HATIPO $\breve{G} L U^{*}$
}

\begin{abstract}
$\ddot{O} Z$
Bu çalışmanın amacı, döviz kuru oynaklı̆̆ının Türkiye'de faaliyet gösteren Katılım bankalarının kredi büyümesi üzerindeki etkisini incelemektir. Bu amaç doğrultusunda, GARCH modeli kullanılarak ilk önce dolar kurunun volatilitesi (oynaklı serisi) elde edilmiş daha sonra ise, basit doğrusal regresyon modeli çerçevesinde, kredi büyüme oranları ile dolar kuru volatilitesi arasındaki ilişki analiz edilmiştir. Çalışmanın sonucunda döviz kuru volatilitesinin, katılım bankalarının kredi büyümesini azalttı̆̆ bulunmuştur. Ekonomi politikaları açısından dĕ̆gerlendirildiğinde, Katılım bankalarının ülkenin reel ekonomisine daha fazla katkı verebilmesi için, döviz kuru oynaklığının azalması gerekmektedir. Bu kapsamda, yerel para biriminden iç tasarrufları teşvik edilmesi, kur beklentilerin düşürülmesi ve merkez bankası rezervlerinin güçlendirilmesi gibi önlemler alınabilir.
\end{abstract}

ANAHTAR KELIMELER

Döviz Kuru Volatilitesi, Katılım Bankaları, Türkiye

\begin{abstract}
The aim of the study is to invastigate the effect of exchange rate volatility on loan growth of Participation banks in Turkey. For this purpose, using the GARCH model, first the volatility of the dollar was obtained and then the relationship between loan growth rates and dollar rate volatility was analyzed within the framework of the simple linear regression model. As a result of the study, it was found that exchange rate volatility decreased the loan growth of Participation banks. As an economic policy implication, in order for Participation banks to contribute more to the real economy, the exchange rate volatility should decrease. In this context, measures such as encouraging domestic savings in local currency, lowering exchange rate expectations and strengthening central bank reserves can be taken.
\end{abstract}

\section{KEYWORDS}

Exchange Rate Volatility, Participation Banks, Turkey

\begin{tabular}{|c|c|c|}
\hline \multicolumn{2}{|c|}{ Makale Geliş Tarihi / Submission Date } & \multicolumn{1}{c|}{$\begin{array}{c}\text { Makale Kabul Tarihi / Date of Acceptance } \\
\text { O1.07.2021 }\end{array}$} \\
\hline \multirow{4}{*}{ Atıf } & $\begin{array}{l}\text { Hatipoğlu, M. (2021). Döviz Kuru Volatilitesinin Katılım Bankalarının Kredileri Üzerine Etkisi. Selçuk Üniversitesi } \\
\text { Sosyal Bilimler Meslek Yüksekokulu Dergisi, 24 (2), 540-547. }\end{array}$ \\
\hline
\end{tabular}

\footnotetext{
* Doç. Dr., Çankırı Karatekin Üniversitesi, IÏBF, İşletme Bölümü, mercanhatipoglu@gmail.com, ORCID: 0000-0003-3307-5458
} 


\section{GíRiș}

Şirketler faaliyetlerini devam ettirebilmek için ihtiyaç duydukları girdi çeşitlerine göre, bilanço yapıları veya nakit akış tablolarındaki farklılıklara bağlı olarak çeşitli finansal risklere maruz kalmaktadırlar. Riskin ne derece tahripkâr olduğu ise mevcut ekonomik koşullara, firmanın likiditesine, sermaye yapısına ve yatırımcıların risk iştahına bağlıdır. Finans piyasalarında sıklıkla karşılaşılan finansal risklerin başında döviz kuru riski gelmektedir. Örneğin, bankalar yeterli düzeyde ihracat geliri olmayan firmalara döviz kredisi kullandırdıklarında ya da bireysel yatırımcılar faiz oranları düşük olduğu için yabancı para cinsinden borçlandıklarında kur riskine maruz kalmaktadırlar. Reel sektörde yer alan firmalar da eğer ithal hammadde kullanıyorlarsa, döviz kurundaki oynaklığa bağlı olarak emtia fiyatlarının değişmesinden dolayı ilave maliyetlere katlanmaktadırlar (Saltoğlu, 2019: 6, 8, 14, 43). Bunun yanında, döviz kuru oynaklığı uluslararası ticarette belirsizlik doğurduğu için, ihracat yapan firmaları iç pazara yönlendirmekte buda dış ticaretin azalmasına yol açmaktadır. Böyle durumlarda devletler yerel firmaların risklerini azaltmak için korumacılık adı altında finansal düzenlemelere başvurmaktadırlar (Ertürk, 2018: 170, 172). Döviz piyasalarında en fazla ithalatçı, ihracatçı, spekülatör ve yatırımcılar işlem yapmaktadırlar. Döviz depolamanın maliyetinin düşük olması, dövizin homojen ve standart olması da döviz piyasasını spekülatif işlemlerin merkezi haline getirmektedir. Döviz kurlarının fiyatının kısa vadeli olarak sürekli değişmesinin arkasında, bir ülkeden diğerine, hiçbir kısıtlama olamadan yönelebilen sermaye hareketleri yer almaktadır. Her işlem günü gerek bireysel gerekse kurumsal müşterilerinin uluslararası işlemlerini gerçekleştirmek için döviz piyasasında faaliyet gösteren bankalar, bilançolarının aktif ve pasif kısmında aynı tutar ve cinste yabancı para bulundurmadıkları zaman yine döviz riskine maruz kalmaktadırlar (Bulut, 2005: 30, 290). Finans sisteminde geleneksel bankaların yanında 1960'lı yıllardan beri katılım bankaları da faaliyet göstermektedir. Özellikle 2008 küresel krizinde bilançolarında türev ürün bulundurmadıkları için, krizde sağlam durmayı başaran katılım bankacılığı, ülkemizde 1984 yılından beri faaliyet göstermektedir (Hatipoğlu, 2019). Bu çalışmada Türkiye'de faaliyet gösteren katılım bankalarının döviz kuru riskinden etkilenip etkilenmediği araştırılmıştır. Bu amaç doğrultusunda katılım bankaları tarafından verilen kredilere döviz kuru volatilitesinin etkisi tespit edilmiştir. GARCH modeli kullanılarak önce dolar kurunun volatilitesi elde edilmiş daha sonra ise, basit doğrusal regresyon modeli çerçevesinde, kredi büyüme oranları ile dolar kuru volatilitesi arasındaki ilişki analiz edilmiştir. Sonuçlar, döviz kuru volatiltesinin katılım bankalarının kredi büyümesini azalttığını göstermiştir.

\section{LITERATÜR}

Gerek döviz kurunun gerekse döviz kuru volatilitesinin birçok makroekonomik değişkene etkisi çeşitli akademik çalışmalara konu olmuştur. Örneğin, Arratibel ve diğ (2011) Orta ve Doğu Avrupa'da yer alıp aynı zamanda $\mathrm{AB}$ üyesi olan ülkelerde düşük döviz kuru volatilitesinin ekonomik büyümeyi hızlandırdığını bulmuştur. Benzer sonuçlara Vieira ve diğ (2013) 1970-2009 arası dönem için 82 ülke kapsamında yaptıkları çalışmalarında da ulaşmışlardır. Ünlü (2016) ARDL modeli ile 1998-2014 dönemi için Türkiye özelinde yaptığı çalışmada, kur volatilitesinin ekonomik büyümeyi düşürdügünden bahsetmiştir. Yazara göre, döviz fiyatlarında gözlemlenen dalgalanmalar geleceğe yönelik belirsizliklerin artması anlamına geldiğinden, girişimciler döviz kuru hakkında net bir kanıya varmak için beklemekte dolayısıyla yatırım kararları mecburen ertelenmekte, buda ekonomik çıktının düşmesine sebep olmaktadır. Gençay (2007) finansal dolarizasyonun para talebinin tahminini zorlaştırdığı için, para politikasının etkinliğini azalttığını ileri sürmüştür. Kandil (2004) döviz kurunun kendi beklenen değeri etrafında yüksek değişkenlik göstermesinin, ekonomik performans üzerinde olumsuz tesirleri olacağını "beklentiler teorisi" çerçevesinde açıklamıştır. Kiyota ve Urata (2004) reel döviz kurundaki oynaklığın doğrudan yabancı yatırımları caydırdığı sonucuna varmıştır. Ozimkovska (2018) hem gelişmiş hem de gelişmekte olan ülkelerde döviz kuru oynaklıklarının portföy yatırımlarını duraksattığını tespit etmiştir. Barguellil ve diğ (2018) gelişen ve gelişmekte olan ülkeler için 1985-2015 dönemini kapsayan çalışmalarında, döviz kuru volatiltesinin ekonomik büyümeyi yavaşlattığını kanıtlamışlardır. Keefe (2020) dinamik panel regresyon modelini kullanarak, enflasyon hedeflemesi rejimine bağl1 13 gelişmekte olan ve 9 gelişmiş ülkeyi kapsayan çalışmasında, döviz kuru volatilitesinin \% 1'in altında olduğunda enflasyon hedeflerini tutturmanın daha kolay olduğunu göstermiştir. Niepmann ve SchmidtEisenlohr (2019) 2011-2016 panel veri modelleri ile yaptıkları çalışmalarında, dolardaki yaklaşık \%10'luk bir değer kaybının ABD bankaları için neredeyse 2,5 milyar dolarlık geç kredi ödemesine yol açtığını hesaplamışlardır. Avdjiev ve diğ (2019) daha güçlü bir doların, dolar cinsinden sınır ötesi bankacılık yapan ülkelerde daha düşük büyüme ile ilişkili olduğunu bulmuşlardır. Karamollaoğlu ve Yalçın (2019) Türkiye'de üretim yapan imalat firmaları için yaptıkları analizlerde, Türk lirasının değer kaybetmesinin firmaların dış rekabet gücü açısından faydalı olduğunu vurgulamışlardır. Shousha (2019) ise Panel-VAR modeli ile yaptı̆̆ çalışmasında doların değer kazanmasının gelişmekte olan ekonomilerde GSYH'da, özel sektör yatırım ve 
kredilerinde kısılmaya yol açtığını, ülke riskinde de artışa sebep olduğunu göstermiştir. Serena ve Sousa (2017) 36 gelişmekte olan ülkede faaliyet gösteren 1000 firma üzerinden yaptıkları çalışmalarında, yerel para biriminden borçlanmaların firma yatırımları üzerinde pozitif etkisi varken, yabancı para biriminden olan borçlanmaların negatif etkisi olduğunu göstermişlerdir. Dada (2020) Sahra Altı Afrika ülkelerinde döviz kuru volatilitesinin bölge içi ticareti daralttığını kanıtlamıştır. Yaşar ve Küpcü (2020) Türkiye'de faaliyet gösteren ve ihracat yapan firmalar için reel döviz kurunun artmasının rekabet avantajını ortadan kaldırdığını ve ihracatın azalmasına yol açtığını savunmuştur. Alp ve Yalçın (2015) yine ülkemiz için 1996-2010 dönemi panel veri kullanarak yaptıkları çalışmalarında, yüksek miktarda yabancı para borcu olan şirketlerin kar marjlarının düşük olduğunu kanıtlamışlardır. Ertürk (2018: 164)'e göre para arzı ve petrol fiyatları gibi değişkenlerin volatilitesini azaltmadan, döviz kurunun refaha etkisi kalıcı olmayacaktır. Héricourt ve Poncet (2015) 100.000 üzerinde Çin firmasını esas alarak 2000-2006 dönemini kapsayan çalışmalarında, döviz kuru volatilitesi arttıkça ihracatın azaldığını ispatlamışlardır. Pradhan ve Hiremath, (2020) göre bankaların ve firmaların döviz ile borçlanmasında 1980'li yıllardan itibaren başlayan finansal liberalleşme süreci de etkili olmuştur. Bu liberalleşmenin bir parçası olarak firmalar uluslararası piyasalardan hem kısa vadeli hem de uzun vadeli finansal ihtiyaçlarını karşılamak için borçlanma imkânına kavuşmuşlardır. On yıllar boyunca özellikle gelişmekte olan ülkeler yüksek dolar borç stokları biriktirmişlerdir. Iyke ve Ho (2020) 1973-2017 arası dönem kapsamında çeyreklik veriler ile Asya bölgesi için yaptıkları araştırmalarında, döviz kuru belirsizliğinin kısa vadede olmasa da, uzun dönemde tüketim harcamalarını azalttığına dair kanıtlar sunmuşlardır. Elhussein ve Osman (2019) Sudan'da faaliyet gösteren 37 bankayı analiz etmişler ve döviz kuru hareketlerinin bankacılık sektöründe öngörülemeyen zararlara neden olduğunu vurgulamışlardır. Bailey ve Chung (1995) döviz kuru riskinin politik riskler ile beraber hisse senetlerinin risk primlerini arttırdığını kaydetmişlerdir.

\section{VERI VE MODEL}

Araştırmada veri olarak, katılım bankalarının dağıttıkları TL cinsinden toplam (yerli + yabancı para cinsinden) kredi miktarı ile ABD dolar kuru kullanılmıştır. Veriler dönem olarak Ağustos 2008 ile Aralık 2020 arasını kapsamakta olup, aylık frekanstadır. Her iki veri de Türkiye Cumhuriyet Merkez Bankası elektronik veri dağıtım sisteminden temin edilmiştir. Malik (2003), Barguellil ve diğ(2018) ve Iyke ve Ho (2020) araştırmalarına uygun olarak bu çalışmada döviz kuru volatilitesi GARCH (Genelleştirilmiş Otoregresif Koşullu Değişen Varyans) modeli ile elde edilmiştir. Engle (2001) tarafından geliştirilen GARCH modelinin en yalın hali aşağıdaki gibidir:

$$
\begin{aligned}
& R_{t}=c+u \\
& \sigma_{t}^{2}=\omega+\alpha \varepsilon_{t-1}^{2}+\beta \sigma_{t-1}^{2}
\end{aligned}
$$

Modelde $\omega$ uzun dönem oynaklığı, $\alpha$ seriye gelen şoklara verilen ani tepkinin büyüklügünü, $\beta$ bir dönem önceki oynaklığın cari oynaklığı ne kadar etkilediğini göstermektedir. GARCH modelinin ekonometrik olarak istikrarlı ve anlamlı olması için $\omega, \alpha, \beta>0$ şartını sağlaması ve kovaryans durağanlık için $\alpha+\beta<1$ kısıtını aşmaması gerekmektedir. Aksi halde, elde edilen parametreler yorumlanamaz (Alexander ve Lazar, 2006). GARCH modellerinin birçok türevi bulunmaktadır. Örneğin EGARCH, GJR-GARCH ya da TGARCH gibi asimetrik volatiliteyi de dikkate alan modeller söz konusudur. Bizim modelimizde asimetriyi ölçen parametre anlamsız çıktığı için rapor edilmemiş, bunun yerine en yalın model olan GARCH $(1,1)$ ile analizlere devam edilmiştir. GARCH modeli ile dolar kuru volatilite serisi elde edildikten sonra, aşağıdaki regresyon modelinden faydalanılmıştır (Mills ve Markellos: 2008, 27-29).

$$
\text { Kredi_büyüme_orant } t=a_{i}+\beta_{t-1} \sum_{i=1}^{t} U S D v o l_{t-1}+\varepsilon_{t}
$$

Modelde Kredi_büyüme_orant , bağımlı değişkeni temsil etmekte olup katılım bankalarının kredi büyüme oranlarını göstermektedir. Söz konusu değişken, $\ln \left(K_{r e d i} /\right.$ Kredi $\left._{t-1}\right)$ formülü ile elde edilmiştir. USDvol $l_{t-1}$ bağımsız değişken olup, döviz kuru volatilitesinin bir gecikmeli değerlerini temsil etmektedir. $U S D v o l$,değişkeni aylık dolar getirisi $R_{t}=\ln \left(\right.$ dolar $_{t} /$ dolar $\left._{t-1}\right)$ formülüne göre hesaplanmıştır. Gecikmeli değerin modelde yer almasının nedeni, yatırımcıların ve bankaların davranışlarını yeni ekonomik gelişmelere göre ayarlamalarının zaman almasıdır (Barro, 1976).

\section{BULGULAR}

Bulgulara geçmeden önce, bağımsız değiş̧ken olan dolar kuru volatilitesinin yapısal özellikleri tablo 1'de sunulmuştur. 
Tablo 1:Döviz Kuru Volatilitesi için GARCH $(1,1)$ Modeli Sonuçları

\begin{tabular}{ccccc}
\hline & Katsay1 & Std. hata & Z-istatistiği & Prob. Değeri \\
\hline $\mathrm{u}$ & 0.008 & 0.003 & 2.663 & 0.007 \\
$\omega$ & 0.000 & 0.000 & 1.919 & 0.054 \\
$\alpha$ & 0.236 & 0.132 & 1.781 & 0.074 \\
$\beta$ & 0.603 & 0.161 & 3.741 & 0.000 \\
\hline Diagnostik testler & & & & \\
\hline ARCH-LM[1] & 0.831 & & & \\
$Q^{2}$ & 0.827 & & & \\
\hline
\end{tabular}

GARCH $(1,1)$ modeli sonuçlarına göre dolar kuru volatilitesi daha çok bir önceki dönemin volatilite değerinden etkilenmektedir. Dolar kurunun getirisindeki \%1'lik artış ise cari volatiliteyi \%0.23 artırmaktadır.

\section{Grafik 1: Dolar Kuru Volatilitesinin 2008-2020 Dönemi Arası Zaman Serisi Grafiği}

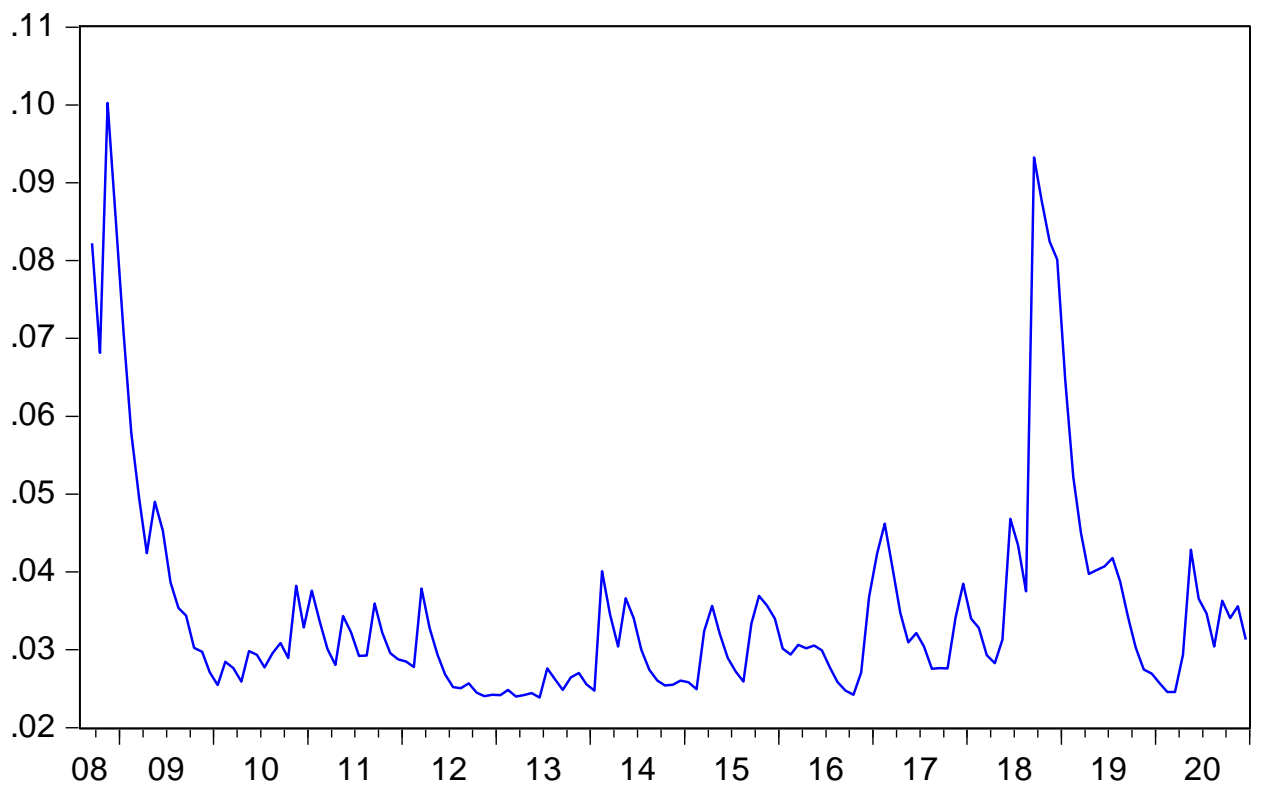

Grafik 1 incelendiğinde ilk göze çarpan nokta, 2008 küresel kriz sonrasındaki aylık neredeyse \%10 seviyesinde gerçekleşen volatiliteye, 2018 yılının ortalarında yeniden rastlanmış olmasıdır. 2008-2018 dönemi arasında dolar kuru volatilitesi aylık olarak \% 4 civarında istikrarlı bir şekilde devam etmiştir. Döviz kuru oynaklığı büyük ölçüde piyasa beklentilerindeki değişmelerden kaynaklanmaktadır. Her ne kadar, para arzı, enflasyon, bütçe açığı ve reel gelir gibi makroekonomik değişkenler de döviz kuru oynaklığı üzerinde etkili olsalar da, döviz kurunun günlük ani düşüş ya da yükseliş hareketlerini açıklamakta yetersiz kalmaktadırlar. Genelde yatırımcılar kararlarını verirken ulaşabildikleri tüm bilgileri dikkate alırlar. Bu yüzden finansal piyasalara her yeni bilgi ulaştığında, yatırımcıların beklentileri yeniden şekillenmektedir. Yeni bilgilerin en önemli kaynağı yürütülen ekonomi politikalarına dair ortaya çıkan yeni haberler veya gelişmelerdir. Örneğin, merkez bankası enflasyon hedefini revize ettiğini açıkladığı zaman veya sermaye araçlarının vergilendirilmesi ile ilgili yeni bir düzenleme yapıldığında döviz kurunun gelecek fiyatına dair beklentiler çabucak değişir ve bu yeni beklentiler döviz kurunun cari fiyatının derhal değişmesine neden olur (Engel ve Hakkio, 1993).

Tablo 2: Değişkenlere Ait Tanımlayıcı İstatistikler

\begin{tabular}{cccccc}
\hline & Ortalama & Std.sapma & Çarpıklık & Basıklık & ADF \\
\hline Kredi Büy_Oran & 0.017 & 0.020 & 0.151 & 4.553 & {$[0.000]$} \\
USDVOL & 0.035 & 0.014 & 2.646 & 10.211 & {$[0.001]$} \\
\hline
\end{tabular}

*Köşeli parantez içindeki sayılar olasılık değerlerini göstermektedir.
Tablo 2'de tanımlayıcı istatistiklere bakıldığında, serilerin ADF birim kök testine göre durağan olduğu görülmektedir. Çarpıklık ve basıklık katsayıları dikkate alındı̆̆ında ise, serilerin normal dağılım sergilemediği göze çarpmaktadır. 
Tablo 3: Dolar Kuru Volatilitesinin Katılım Bankalarının Kredi Büyümesine Etkisi

\begin{tabular}{|c|c|c|c|c|}
\hline Değişken & Katsayı & Std. hata & t-istatistği & Olasılık değeri \\
\hline USDVOL(-1) & -0.778 & 0.281 & -2.764 & 0.006 \\
\hline USDVOL(-2) & 0.281 & 0.369 & 0.762 & 0.447 \\
\hline USDVOL(-3) & 0.206 & 0.368 & 0.561 & 0.575 \\
\hline USDVOL(-4) & -0.355 & 0.371 & -0.957 & 0.340 \\
\hline USDVOL(-5) & 0.296 & 0.379 & 0.780 & 0.436 \\
\hline USDVOL(-6) & 0.240 & 0.379 & 0.634 & 0.527 \\
\hline USDVOL(-7) & -0.128 & 0.375 & -0.341 & 0.733 \\
\hline USDVOL(-8) & 0.119 & 0.381 & 0.314 & 0.753 \\
\hline USDVOL(-9) & -0.563 & 0.378 & -1.488 & 0.139 \\
\hline USDVOL $(-10)$ & 0.159 & 0.348 & 0.457 & 0.647 \\
\hline USDVOL(-11) & 0.310 & 0.321 & 0.965 & 0.336 \\
\hline USDVOL(-12) & 0.102 & 0.240 & 0.426 & 0.670 \\
\hline $\mathrm{C}$ & 0.020 & 0.007 & 2.805 & 0.005 \\
\hline \multicolumn{5}{|l|}{ Diagnostik testler } \\
\hline Gözlem sayısı & 136 & & & \\
\hline$R^{2}$ & 0.161 & & & \\
\hline F İstatistiği & 1.974 & & & \\
\hline F Olasılık Değeri & 0.031 & & & \\
\hline LM testi & 0.311 & & & \\
\hline BPG testi & 0.623 & & & \\
\hline AIC & -4.941 & & & \\
\hline $\mathrm{SC}$ & -4.663 & & & \\
\hline
\end{tabular}

Tablo 3'te regresyon modeli çerçevesinde döviz kuru volatilitesinin katılım bankalarının kredi büyümesine olan etkisi sunulmuştur. Tabloya bakıldığında, dolar kurunun bir gecikmeli volatilitesindeki \%1'lik artış, katılım bankalarının kredi büyümesini aylık olarak \%0.77 oranında azaltmaktadır. Çünkü döviz kuru istikrarsızlığ , risk primini ve faiz oranlarını artırarak kredi büyümesini engellemektedir (Arratibel ve diğ2011). Bununla beraber, dolar borç oranı yüksek olan firmaların daha az yatırım yapma eğiliminde olduğu için, banka kredilerinin azalacağı Carranza ve diğ(2003) çalışmasında gösterilmiştir. Öte yandan, dolar kurunun diğer gecikmeli etkileri kredi büyüme oranında istatistiksel olarak anlamlı bir etkiye sahip değildir. Yani, Ocak ayında gerçekleşen dolar kuru volatilitesi Şubat ayındaki kredi büyümesini örselerken, Mart ayındaki ve diğer aylardaki kredi hacmi üzerinde herhangi bir etkisi yoktur. Diğer bir anlatımla, dolar kurundaki volatilitenin etkisi bir ay sonra sönümlenmektedir. Regresyon modelinin $R^{2}$ değerine bakıldığında dolar kuru volatilitesi katılım bankalarındaki kredi değişiminin yaklaşı \%16'sını açıklamaktadır. Modelde otokorelasyon ve değişen varyans sorunlar olmadığı sırasıyla LM ve BPG testlerinden görülmektedir. Pradhan ve Hiremath (2020) göre bir firmanın borçlanacağ para birimi seçimi, beklenen borçlanma maliyetine bağl1 olmanın yanında, firmaya özgü talep yönlü faktörlerden ve çeşitli makroekonomik faktörlerden de etkilenmektedir. Örneğin, firmanın kendi özelliklerine göre, aktif büyüklüğü arttıkça yabancı para tutma kabiliyeti artacağı için dolar borçlanması daha kolay olmaktadır. Öte yandan, ihracat geliri olan firmalar nispeten daha yüksek bir dolar borcuna sahiptir. Çünkü ihracat satışları, bu tür bir borca karşı bir teminat veya doğal koruma işlevi görür. Sinyal teorisine göre firmalar bilançolarının sağl1klı ve güçlü olduğunu bankalara göstermek için yabancı para cinsinden bono ve tahvil düzenleyebilirler. Yine, düşük kaldıraç oranlarına sahip firmalar yabancı para borçlanmasına gitmektedirler. Makroekonomik değişkenler açısından ise, faiz oranlarından kaynaklı olarak yurtdışı borçlanmanın maliyeti düşük olduğunda firmalar tereddüt etmeden yabancı para cinsinden borçlanmaktadırlar. İlave olarak, döviz kurunun değer kaybetmesi, firmaların tercihleri etkileyen başka bir makroekonomik faktördür. Dövizdeki değer kazancı, teminatın değerini arttırıp, borçlunun temerrüt olasılığını düşürdüğü için, yabancı para borçlanması ve döviz kurunun değerlenmesi arasındaki ilişki pozitiftir.

\section{SONUÇ}

Günümüzde bir paranın arkasında devletin olması ne yazık ki, o paranın finansal (borçlanma vb.) ya da ekonomik (kira vb.) işlemlerde tercih edilmesi için tek başına yeterli olmamaktadır. Eğer bir ülkede paranın değerini koruyamayacağı inancı piyasaya hâkim olmaya başlarsa, uzun vadeli sözleşmeler yabancı para cinsinden veya altın fiyatlarına endeksli olmaya başlar. Bunun yanında, banka müşterileri, mevduatlarının en yüksek getiri ile korunması beklerken, finans kurumundan borçlanırken de en düşük maliyetle işini halletmek niyetindedir. Genelde, banka bilançoları menkul değerleri içerdiği için, günlük olarak yaşanan kur, faiz ya da 
diğer ekonomik gelişmeler nakit akışlarını etkilemektedir (Söylemezoğlu, 2020: 48, 201, 202). Türkiye'de katılım bankaları geleneksel bankalar ile rekabet ederken yukarıda sayılan nedenler de dikkate alındığında, faaliyetlerine zor şartlar altında devam etmektedirler. Bu çalışmada döviz kuru volatilitesinin katılım bankalarının kredi büyümesine olan etkisi araştırılmıştır. Çalışmanın sonucunda döviz kuru volatilitesinin, katılım bankalarının kredi büyümesini azalttığı bulunmuştur. Dolayısıyla katılım bankacılığının ülkemizde büyümesi için kurdaki volatilitenin düşürülmesi gerekmektedir. Literatür incelendiğinde döviz kuru volatilitesini düşürmek için bazı araştırmalarda çeşitli önerilerde bulunulmuştur. Örneğin, Engel ve Hakkio (1993)'e göre döviz kuru volatilitesi makroekonomik değişkenlerin ve piyasa beklentilerindeki değişmelerden kaynaklandığı için, her iki faktörün gelecek değerlerine dair beklentilerin ekonomi politikası yetkilileri tarafindan düşürülmesi, döviz kurunun oynaklığını azaltacaktır. İhtiyati tedbirler olarak, yapısal reformlar takip edilerek, makroekonomik düzeyde para birimi uyuşmazlığı reel sektör firmaları için azaltılmalıdır. Aynı zamanda, ekonominin dedolarizasyonunu hedefleyen piyasa dostu stratejiler izlenmelidir. Bu stratejiler, yerel para biriminde iç tasarrufları teşvik etmeye dayanmalıdır. Örneğin, tasarruf aracı olarak enflasyona endeksli devlet tahvilleri ihraç etmek ve ihracat yapmayan firmalara döviz kredisi kullanımı zorlaştırmak söz konusu stratejiler kapsamında düşünülebilir (Carranza ve diğ2003). Yine literatürde döviz kuru volatilitesini azaltmak için merkez bankası rezervlerinin kullanılabileceği vurgulanmıştır (Hviding ve diğ2004). Birinci olarak rezervlerinin, olası kur krizlerine ya da uluslararası kreditörlerin belirsizlik dönemlerindeki ani fon kesintilerine karşı, kredilerin yenilenmesinde işe yaradığı gösterilmiştir. İkinci olarak ise, daha yüksek rezerv yeterliliği, daha düşük borçlanma maliyeti anlamına gelmektedir. Çünkü yeterli düzeyde merkez bankasında rezerv tutmak, devletin yabancı paralar cinsinden olan borçlarını ödemede temerrüde düşme riskini azalttığ1 için, hem uluslararası yatırımcının güveni artmakta hem de borçlanma maliyetleri düşmektedir. Son olarak, merkez bankasının rezervi ne kadar yüksekse, döviz kurundaki istikrarsızlığı düzeltmek için döviz piyasasına müdahale imkânı da o nispette artmaktadır. 


\section{KAYNAKÇA}

Alexander, C., ve Lazar, E. (2006). Normal mixture GARCH (1, 1): Applications to Exchange Rate Modelling. Journal of Applied Econometrics, 21(3), 307-336.

Alp, B., ve Yalçın, C. (2015). Türkiye'de Şirketlerin Borç Dolarizasyonu ve Büyüme Performansı. TCMB Çalışma Tebliği, 15(01), 1-41.

Arratibel, O., Furceri, D., Martin, R., ve Zdzienicka, A. (2011). The Effect of Nominal Exchange Rate Volatility on Real Macroeconomic Performance in the CEE Countries. Economic Systems, 35(2), 261-277.

Avdjiev, S., Bruno, V., Koch, C., ve Shin, H. S. (2019). The Dollar Exchange Rate As a Global Risk Factor: Evidence from Investment. IMF Economic Review, 67(1), 151-173.

Bailey, W., ve Chung, Y. P. (1995). Exchange Rate Fluctuations, Political Risk, and Stock Returns: Some Evidence from an Emerging Market. Journal of Financial and Quantitative Analysis, 541-561.

Barguellil, A., Ben-Salha, O., ve Zmami, M. (2018). Exchange Rate Volatility and Economic Growth. Journal of Economic Integration, 33(2), 1302-1336.

Barro, R. J. (1976). Rational Expectations and the Role of Monetary Policy. Journal of Monetary Economics, 2(1), 1-32.

Bulut, E. (2005). Döviz ekonomisi (Piyasanın Mikro Yapısı). Platin Yayınları: Ankara

Carranza, L. J., Cayo, J. M., ve Galdón-Sánchez, J. E. (2003). Exchange Rate Volatility and Economic Performance in Peru: A Firm Level Analysis. Emerging Markets Review, 4(4), 472-496.

Dada, J. T. (2020). Asymmetric Effect of Exchange Rate Volatility on Trade in Sub-Saharan African Countries. Journal of Economic and Administrative Sciences. ISSN: 1026-4116

Elhussein, N. H. A., ve Osman, O. E. E. (2019). Exchange Rate Fluctuations and Financial Performance of Banks: Evidence from Sudan. International Journal of Economics and Finance, 11(12), 15-27.

Engel, C., ve Hakkio, C. S. (1993). Exchange Rate Regimes and Volatility. Economic Review-Federal Reserve Bank of Kansas City, 78, 43-43.

Engle, R. (2001). GARCH 101: The Use of ARCH/GARCH Models in Applied Econometrics. Journal of Economic Perspectives, 15(4), 157-168.

Ertürk, E.(2018). Döviz Ekonomisi. Ekin Yayınları:Bursa

Gençay, O. (2007). Finansal Dolarizasyon ve Finansal İstikrar Arasındaki İlişki: Türkiye Değerlendirmesi. TCMB Uzmanlık Yeterlilik Tezi.

Hatipoğlu, M. (2019). Dünyada ve Türkiye'de İslami Finans. Ekin Yayınevi: Bursa

Héricourt, J., ve Poncet, S. (2015). Exchange Rate Volatility, Financial Constraints, and Trade: Empirical Evidence from Chinese Firms. The World Bank Economic Review, 29(3), 550-578.

Hviding, K., Nowak, M., ve Ricci, L. A. (2004). Can Higher Reserves Help Reduce Exchange Rate Volatility?. IMF Working paper. WP/04/189.

Iyke, B. N., ve Ho, S. Y. (2020). Consumption and Exchange Rate Uncertainty: Evidence from Selected Asian Countries. The World Economy, 43(9), 2437-2462.

Kandil, M. (2004). Exchange Rate Fluctuations and Economic Activity in Developing Countries: Theory and Evidence. Journal of Economic Development, 29, 85-108.

Karamollaoğlu, N., ve Yalçın, C. (2019). Exports, Real Exchange Rates and Dollarization: Empirical Evidence from Turkish Manufacturing Firms. Empirical Economics, 1-31.

Keefe, H. G. (2020). The Impact of Exchange Rate Volatility on Inflation Targeting Monetary Policy in Emerging and Advanced Economies. International Finance, 23(3), 417-433.

Kiyota, K., ve Urata, S. (2004). Exchange Rate, Exchange Rate Volatility and Foreign Direct Investment. World Economy, 27(10), 1501-1536.

Malik, F. (2003). Sudden Changes in Variance and Volatility Persistence in Foreign Exchange Markets. Journal of Multinational Financial Management, 13(3), 217-230.

Mills, T. C., ve Markellos, R. N. (2008). The Econometric Modelling of Financial Time Series. Cambridge University Press: UK

Niepmann, F., ve Schmidt-Eisenlohr, T. (2019). Foreign Currency Loans and Credit Risk: Evidence from U.S. Banks. CEPR Discussion Paper No. DP14212,

Ozimkovska, V. (2018). Real Financial Market Exchange Rate Volatility and Portfolio Flows. International Economics and Economic Policy, 15(2), 281-303.

Pradhan, A. K., ve Hiremath, G. S. (2020). Why Do Indian Firms Borrow in Foreign Currency?.The Journal of Applied Economic Research, 14(2), 191-211.

Saltoglu, B. (2019). Finansal Risk Yönetimi .Alef Yayınevi. İstanbul

Serena, J.M. ve Sousa, R. (2017). Does Exchange Rate Depreciation Have Contractionary Effects on Firm-Level Investment?. BIS Working Paper No. 624.

Shousha, S. (2019). The Dollar and Emerging Market Economies: Financial Vulnerabilities Meet the International Trade System. International Finance Discussion Papers 1258.

Söylemezoğlu, A. (2020). Küresel Ekonomi Düzeni Kurumlar ve Kurallar. Remzi Yayınevi:İ́stanbul

Ünlü, H. (2016). Döviz Kuru Oynaklığı ve Ekonomik Büyüme: Türkiye Örneği. Sosyoekonomi, 24(27), 11-24. 
Vieira, F. V., Holland, M., Da Silva, C. G., ve Bottecchia, L. C. (2013). Growth and Exchange Rate Volatility: A Panel Data Analysis. Applied Economics, 45(26), 3733-3741.

Yaşar, E., ve Küpcü, O.(2020). Reel Döviz Kurunun Firmaların İhracat Performansına Etkisi: Farklı Sektörlerdeki Firmalar Üzerine Ampirik Bir İnceleme. Balkan ve Yakın Doğu Sosyal Bilimler Dergisi.(6). 